\title{
Production of iturin A through glass column reactor (GCR) from soybean curd residue (okara) by Bacillus subtilis RB14-CS under solid state fermentation (SSF)
}

\author{
Abdul Wahab Khan ${ }^{1,2 *}$, Umme Salma Zohora ${ }^{1,3}$, Mohammad Shahedur Rahman ${ }^{1,4}$, \\ Masahiro Okanami ${ }^{5}$, Takashi Ano ${ }^{1,5}$ \\ ${ }^{1}$ Chemical Resources Laboratory, Tokyo Institute of Technology, Yokohama, Japan \\ ${ }^{2}$ Agriculture Group, Alps Business Creation Co., Ltd., Kawasaki, Japan \\ ${ }^{3}$ Proximo Biotech Ltd., Dinajpur, Bangladesh \\ ${ }^{4}$ Department of Biotechnology and Genetic Engineering, Faculty of Biological Sciences, Jahangirnagar University, Dhaka, Bangla- \\ desh \\ ${ }^{5}$ Department of Biotechnological Science, Faculty of Biology-Oriented Science and Technology, Kinki University, Kinokawa, \\ Japan \\ Email: ${ }^{k}$ khan.abdulwahab@gmail.com
}

Received 18 January 2012; revised 23 February 2012; accepted 3 March 2012

\begin{abstract}
The present study was conducted with an aim to scale up the production of iturin $A$ using soybean curd residue (okara). Iturin A was produced by indigenous bacterial strain Bacillus subtilis RB14-CS through glass column reactor (GCR) under solid state fermentation (SSF) was characterized. The enhanced iturin A production was observed with respect to enhanced substrate bed height when SSF was conducted in Erlenmeyer flask. To check the effect of substrate bed height on iturin A production under SSF of okara, GCR was introduced. Substrate bed height of $15 \mathrm{~cm}$ was suitable for iturin A production which was about $2700 \mathrm{mg} / \mathrm{kg}$ wet substrate. The observed iturin A production by the aerobic bacteria Bacillus subtilis in nearly anaerobic condition in such high substrate bed for SSF is a wonderful finding for development of SSF system in future.
\end{abstract}

Keywords: Solid State Fermentation; Okara; Iturin A; Glass Column Reactor

\section{INTRODUCTION}

The extensive human activities in agriculture and food industries produce a substantial amount of waste. These wastes have become no longer negligible to the atmosphere. Therefore, it is necessary to develop optimized system for waste management. Probably the only solution for the decent waste management is the recycling of waste. Agriculture and food industries wastes, for exam-

"Corresponding author. ple, wheat straw, rice hulls, corn cobs and okara are being recycled as solid substrates for SSF [1-3]. This process requires relatively low energy whereas produces higher concentrated products. Foods, feeds, fuel, enzymes and antibiotics have been produced through SSF $[1,2]$.

The residue left from ground soy beans after extraction of the water extractable fraction used to produce soy milk or tofu, is called okara. About $1.1 \mathrm{~kg}$ of fresh okara is produced from every kilogram of soybean processed into soymilk or tofu [4]. Annually about 0.7 million tons of okara is produced as byproduct of tofu manufacture and most of it has been incinerated as waste [2]. Okara is rich in water-insoluble ingredients (protein $(4.8 \%)$, fat (3.6\%), starch and sugar (6.4\%), fiber (3.3\%), ash (0.8\%) and water $(81 \%)$ ) making it a potentially useful substrate for microbial fermentation [5]. In our laboratory okara has been successfully used by several researchers $[2,6]$ for SSF, but very little work has been conducted to scale up SSF and iturin A production.

The wild strain B. subtilis RB14 utilized in previous works produced iturin A and surfactin [7]. In plate assay it was found that purified iturin A inhibited a good number of plant pathogenic fungal growth [8]. Iturin A shows strong antibiotic activity than that of surfactin [9]. Iturin $\mathrm{A}$ is a cyclolipopeptide containing seven residues of $\alpha$-amino acids (L-Asn-D-Tyr-D-Asn-L-Gln-L-Pro-D-AsnL-Ser-) and one residue of a $\beta$-amino acid is likely to be the active agents in biological control [10]. There- fore, the single iturin A producer $B$. subtilis RB14-CS was used in this study for utilization of okara and iturin A production. RB14-CS is a spontaneous mutant derived from RB14-C and was selected by morphological change 
of RB14-C in colony formation. B. subtilis RB14-C is a streptomycin resistant mutant from a parent strain RB14 and is a coproducer of the antibiotics iturin A and surfactin $[9,11]$.

When SSF was conducted in Erlenmeyer flasks, interesting effects of substrate bed heights on iturin A production were observed. To check the effect of substrate bed height on secondary metabolite, lipopeptide antibiotics iturin A production, glass columns were introduced as reactors.

\section{MATERIALS AND METHODS}

Okara was used as substrate for SSF which was collected from Marusho Shoten (Machida, Tokyo). Small packets (150 to 200 g) were made by using commercially available plastic bags and were stored at $-20^{\circ} \mathrm{C}$ for experimental use. The frozen okara was kept at room temperature to be thawed. Thawed okara was taken in $1000 \mathrm{~mL}$ beaker and autoclaved twice at $120^{\circ} \mathrm{C}$ for $20 \mathrm{~min}$ at an interval of 8 - $12 \mathrm{~h}$.

\subsection{Microorganism and Liquid Inoculum Preparation}

B. subtilis RB14-CS culture was grown overnight at $30^{\circ} \mathrm{C}$ at 120 stroke per minute (spm) in $18 \mathrm{~mm}$ test tubes using L medium (1\% Polypepton (Nippon Pharmaceuticals Co., Tokyo), 0.5\% yeast extract (Oriental Yeast Co., Tokyo), $0.5 \% \mathrm{NaCl}, \mathrm{pH} 7.0$ ) and $1 \mathrm{~mL}$ of it was used for preparation of $100 \mathrm{~mL}$ of preculture in Sakaguchi flask using No.3S medium (3\% Polypepton S (Nippon Pharmaceuticals Co., Tokyo), 1\% Glucose (Kanto Chemical Co., Tokyo), $0.1 \% \mathrm{KH}_{2} \mathrm{PO}_{4}$ (Kanto Chemical Co., Tokyo), $0.05 \% \mathrm{MgSO}_{4} \cdot 7 \mathrm{H}_{2} \mathrm{O}$ (Kanto Chemical Co., Tokyo), $\mathrm{pH} 6.8$ ) at $30^{\circ} \mathrm{C}$ and at $120 \mathrm{spm}$ for $24 \mathrm{~h}$.

\subsection{Experimental Setup for SSF in Erlenmeyer Flasks and GCR}

The 100, 300 and $1000 \mathrm{ml}$ Erlenmeyer flasks, glass columns, cotton plugs, saran nets and silicon plugs were autoclaved and dried before use.

Preculture, 20\% (v/w) of liquid inoculum was added to solid substrate okara which was supplemented with 5.5\% (v/w) of $2.5 \mathrm{M}$ glucose; $0.5 \%(\mathrm{v} / \mathrm{w})$ of $1 \mathrm{M} \mathrm{KH}_{2} \mathrm{PO}_{4} ; 1 \%$ (v/w) of $1 \mathrm{M} \mathrm{MgSO}_{4} \cdot 7 \mathrm{H}_{2} \mathrm{O}$ and $2.45 \%$ (v/w) of water. The final moisture content of the substrate became $79 \%$.

The properly mixed, supplemented and inoculated okara was aseptically transferred into the $100 \mathrm{~mL}, 300$ $\mathrm{mL}$ and $1000 \mathrm{~mL}$ Erlenmeyer flasks at different quantity. The flasks were covered by sterile silicon caps.

GCR is very simple in construction. The main part of the GCR is its long hollow glass column which was filled with substrate for fermentation. The diameter and height of the hollow columns were $5.5 \mathrm{~cm}$ and $30 \mathrm{~cm}$ respectively. The bottom side of the glass column was blocked by silicon rubber cap and the top of the column was covered with cotton plug (Figure 1). Every $5 \mathrm{~cm}$ height of the column of the GCR can contain about $50 \mathrm{~g}$ of substrate. GCRs and flasks were incubated in a water bath at $25^{\circ} \mathrm{C}$ for 6 days.

\subsection{Determination of Viable Cell Number and pH}

After sixth day of its cultivation the fermented products of the flasks and columns were taken into sterile beaker and mixed thoroughly with sterile spatulas. $1 \mathrm{~g}$ of mixed product was taken into a sterile test tube (18 mm diameter) and added $9 \mathrm{~mL}$ of sterile distilled water. It was mixed thoroughly by using vortex and water bath shaker (150 spm for $5 \mathrm{~min}$ ) at room temperature. Culture mix was serially diluted and was spread on agar plate for total cell while culture mix was heated at $80^{\circ} \mathrm{C}$ for $10 \mathrm{~min}$ before spreading for spore count. The cell suspension obtained for CFU measurement was used for $\mathrm{pH}$ measurement [10].

\subsection{Determination of Iturin A Concentration}

For iturin A extraction, 15 gm of fermented product was taken into $100 \mathrm{~mL}$ Erlenmeyer flasks and $45 \mathrm{~mL}$ of HPLC grade methanol was added. It was mixed thoroughly by shaking at $150 \mathrm{spm}$ for $1 \mathrm{~h}$ at room temperature. From the homogenized sample, $1000 \mu \mathrm{l}$ was transferred into $1.5 \mathrm{~mL}$ polypropylene tube. The samples were vortexed at room temperature for $20 \mathrm{~min}$ and then centrifuged at $15,000 \times \mathrm{g}$ for $10 \mathrm{~min}$ at $4^{\circ} \mathrm{C}$. The supernatant was filtrated through $0.20 \mu \mathrm{m}$ polytetrafluoro ethylene (PTFE) membrane filter (Advantec, Tokyo, Japan) and $20 \mu \mathrm{l}$ of the filtrate was injected into HPLC column for iturin A detection. A mixture of acetonitrile and 10

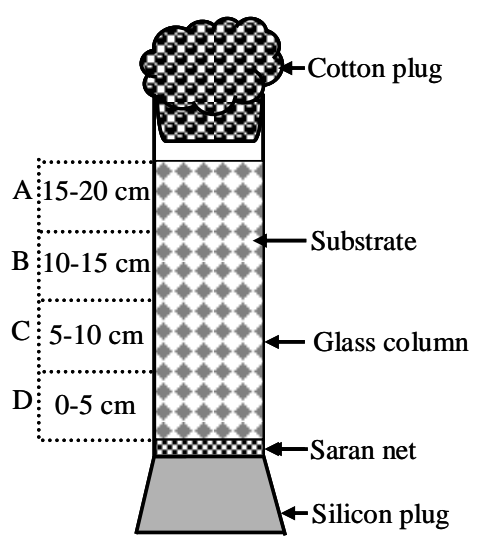

Figure 1. Glass column reactor (GCR). This column was segmented in to four equal parts, each of them was $5 \mathrm{~cm}$ and denoted as “A”, “ $B$ ”, “ $C$ ” \& “ $D$ ” from top to bottom respectively. 
$\mathrm{mM}$ ammonium acetate (35:65, v/v) was used in mobile phase through ODS column (chromolith performance RP-18e 100 - 4.6 mm, Merck KGaA, Darmstadt, Germany) at a flow rate of $2 \mathrm{~mL} / \mathrm{min}$ at $30^{\circ} \mathrm{C}$ [10].

\subsection{Resazurin Test for Determination of Dissolved Oxygen Concentration}

Resazurin 0.5 g (resazurin sodium salt, Kanto Chemicals Co., Inc. Tokyo) was dissolved with the distilled water of $500 \mathrm{~mL}$ and stored it in a brown reagent bottle at $4^{\circ} \mathrm{C}$ in a refrigerator.

Resazurin solution was used to check oxygen depletion gradient in $20 \mathrm{~cm}$ high substrate bed in GCR system. Resazurin solution was sterilized at $121^{\circ} \mathrm{C}$ for $20 \mathrm{~min}$ and added $[2 \%(\mathrm{v} / \mathrm{w})]$ to the substrate okara. A control column was also set without microorganism.

\section{RESULTS AND DISCUSSION}

\subsection{Effect of Substrate Quantity and Height on Iturin A Production}

B. subtilis RB14-CS is an aerobic bacterium, therefore, it was thought that the increased substrate bed height might create more anaerobic condition into substrate bed and production of iturin A would be reduced. The scale up of substrate bed height was never tried before for SSF of okara.

SSF of okara was first conducted in $100 \mathrm{~mL}$ Erlenmeyer flask with $15 \mathrm{~g}$ of okara [2]. The gradual increases of the substrate quantity as well as substrate bed height were observed to achieve the scale up of substrate use and iturin A production. SSF of 10, 15, 20, 25 and $30 \mathrm{~g}$ of okara in $100 \mathrm{~mL}$ Erlenmeyer flasks were conducted and the iturin A production were found to be similar regardless of the volume of okara and it was about 2000 $\mathrm{mg} / \mathrm{kg}$ wet okara (Figure 2). When the substrate quantity was doubled compare to initial $15 \mathrm{~g}$ of substrate, no major difference was observed for iturin A production,

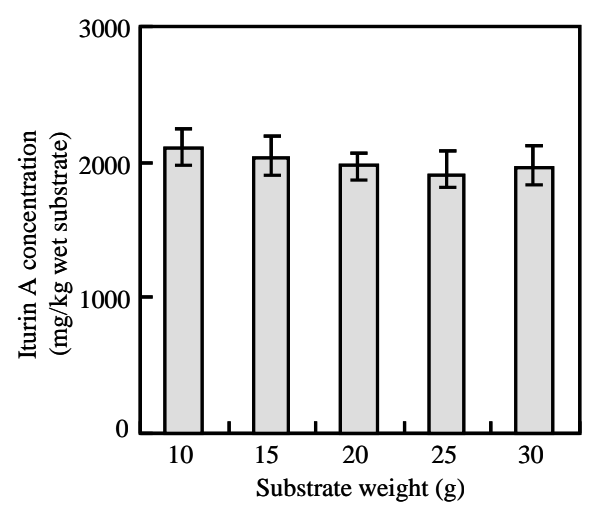

Figure 2. Effect of substrate (okara) weight on iturin A production by SSF in $100 \mathrm{~mL}$ Erlenmeyer flasks. therefore, further scale up of the substrate quantity was aimed and iturin A production was checked.

Substrate weight $30 \mathrm{~g}$ was the possible maximum amount of substrate in $100 \mathrm{~mL}$ Erlenmeyer flasks, so SSF of $45 \mathrm{~g}, 90 \mathrm{~g}$ and $120 \mathrm{~g}$ of substrate were conducted in $300 \mathrm{~mL}$ Erlenmeyer flaks. Though $45 \mathrm{~g}$ of substrate showed similar iturin A production of $15 \mathrm{~g}$ substrate, whereas, $90 \mathrm{~g}$ and $120 \mathrm{~g}$ of substrate showed better production (2800 mg/kg wet substrate) than 15 g substrate (Figure 3).

Further scale up of substrate for SSF was conducted in $1000 \mathrm{~mL}$ Erlenmeyer flasks with 150, 300 and $450 \mathrm{~g}$ of substrate. The maximum iturin A production was observed during its sixth day of cultivation (Figure 4). In this experiment, different weights of the substrate (minimum $10 \mathrm{~g}$ to maximum $450 \mathrm{~g}$ ) were used for SSF in different flasks.

The maximum amount of substrate in the largest Erlenmeyer flask also gave the maximum height of substrate bed. In $100 \mathrm{~mL}$ Erlenmeyer flasks $10 \mathrm{~g}$ of okara formed $1 \mathrm{~cm}$ high bed while $450 \mathrm{~g}$ of okara in $1000 \mathrm{~mL}$ Erlenmeyer flasks formed about $9 \mathrm{~cm}$ high bed, these results strongly support that substrate bed height has an important influence during SSF of okara on iturin A production by using $B$. subtilis RB14-CS (Table 1). It was thought that such a big height might create adverse condition for microbial metabolism and iturin A production. However it showed its best production on the contrary of those assumptions (Figure 4). During the fermentation, the medium $\mathrm{pH}$ declined due to acid production by consumption of carbon substrates during the growth of vegetative RB14-CS cells. Then, $\mathrm{pH}$ increased mainly by ammonification of degradation of nitrogenous compounds in okara (Figure 4).

Due to the conical structure of Erlenmeyer flask, enhancement of substrate bed height was not possible to check the effect of substrate bed height on iturin A pro-

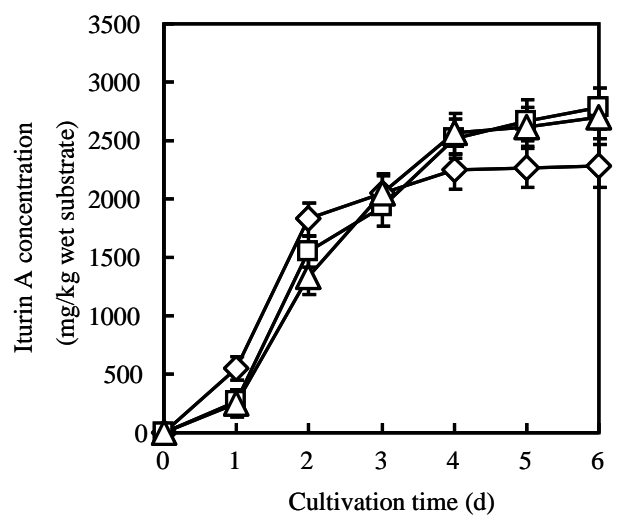

Figure 3. Iturin A production when SSF was conducted in $300 \mathrm{~mL}$ Erlenmeyer flask with 45 (dimond), 90 (square) and 120 (triangle) g of (okara) substrate. 


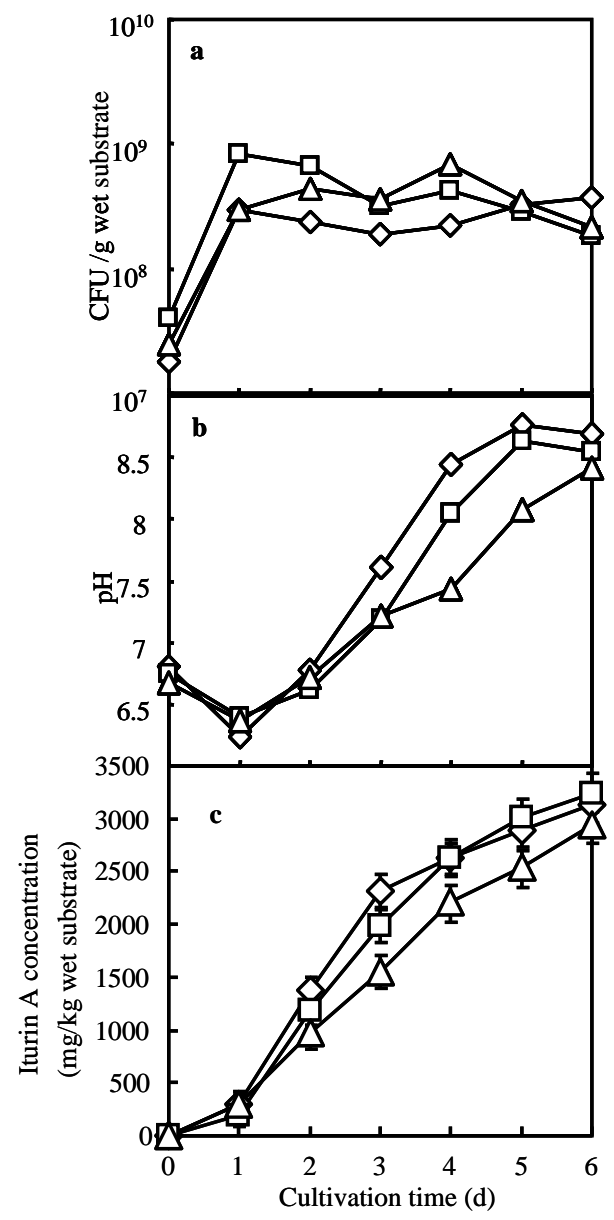

Figure 4. SSF in $1000 \mathrm{ml}$ Erlenmeyer flask with 150 (diamond), 300 (square) and 450 (triangle) g of (okara) substrate where colony forming units (a), $\mathrm{pH}$ (b) and iturin A production (c) are shown.

Table 1. Comparison of substrate bed weight, height and their iturin A production.

\begin{tabular}{cccc}
\hline $\begin{array}{c}\text { Fermenter size }(\mathrm{mL}) \\
\text { (Erlenmeyer flask) }\end{array}$ & $\begin{array}{c}\text { Substrate } \\
\text { weight }(\mathrm{g})\end{array}$ & $\begin{array}{c}\text { Substrate bed } \\
\text { height }(\mathrm{cm})\end{array}$ & $\begin{array}{c}\text { Iturin A production } \\
\text { (mg/kg wet } \\
\text { substrate) }\end{array}$ \\
\hline 100 & 10 & 1 & 2000 \\
1000 & 450 & 9 & 3250 \\
\hline
\end{tabular}

duction. Substrate bed area was not same at all height levels of substrate bed in Erlenmeyer flask. Therefore, oxygen homogeneity was not possible into the whole substrate bed. For these reasons, glass column was selected as reactor for its uniform structure.

\subsection{Observation of Substrate Bed Height Effect in GCR}

Substrate bed heights $5 \mathrm{~cm}, 10 \mathrm{~cm}, 15 \mathrm{~cm}$, and $20 \mathrm{~cm}$ were applied for GCR. The average iturin A production increased with the increasing substrate bed height up to
$15 \mathrm{~cm}$. Heights more than $15 \mathrm{~cm}$ showed lower production than $15 \mathrm{~cm}$ height substrate bed. The average iturin A produced in $5 \mathrm{~cm}, 10 \mathrm{~cm}, 15 \mathrm{~cm}$, and $20 \mathrm{~cm}$ substrate bed were 1990, 2650, 2720 and $2220 \mathrm{mg} / \mathrm{kg}$ wet substrate respectively.

Iturin A production at different bed heights was not uniform. The lower part of the GCR might be less aerobic than the top part, for this reason differences in production in column substrate bed was observed. Substrate bed was divided into four equal parts and denoted as A, B, C and D from top to bottom respectively as shown in Figure 1. The average iturin A production of $20 \mathrm{~cm}$ high substrate bed decreased due to very low production (Figure 5(a)) at bottom part (part D, Figure 1) of the substrate bed. The trend of increasing Iturin A production was observed up to $15 \mathrm{~cm}$ substrate bed height. The average iturin A production in $15 \mathrm{~cm}$ high substrate bed and the average iturin A production in top three parts of the $20 \mathrm{~cm}$ high substrate bed were same. Iturin A production might be affected by oxygen deficiency at the bottom part of the $20 \mathrm{~cm}$ high substrate bed.

According to research of Phae et al. (1991) lower aeration rate was favorable for a higher production of iturin, indicating that an increase of oxygen supply gave no stimulation to the increase of iturin production, even for an obligate aerobe, $B$. subtilis NB22 [12]. Incase of SSF of $B$. subtilis RB14-CS in GCR, same phenomena was observed. Hypothetically part " $\mathrm{A}$ " should be more aerobic compare to part " $B$ ", whereas part " $B$ " showed better iturin A production than that of part " $\mathrm{A}$ ".

The top part of the substrate bed was more alkaline than the bottom part and at that part all the vegetative cells became spores. At bottom part of substrate bed low vegetative cell growth was observed compared to top part, whereas ten times lower sporulation was observed at bottom part compared to its vegetative growth (Figure 5(b)).

\subsection{Determination of Depletion Rate of Oxygen in GCR}

Differences on iturin A production at the different hights of substrate bed, seemed to be the effect of oxygen depletion. Therefore resazurin solution was added to observe the oxygen depletion in GCR system. Resazurin works as a color indicator. In presence of oxygen, oxidized resazurin produces dark blue color. On the other hand when oxygen decreases, resazurin is reduced to pink colored resorufin and its further reduction to hydroresorufin turned the column uncolored [13].

The color of substrate bed in the control column remained blue during the experimental period, whereas the color of the inoculated column changed gradually (Figure 6). Hourly observations were conducted at 0 , 2nd, 6th, 11th, 18th and 29th h. Color change was observed 


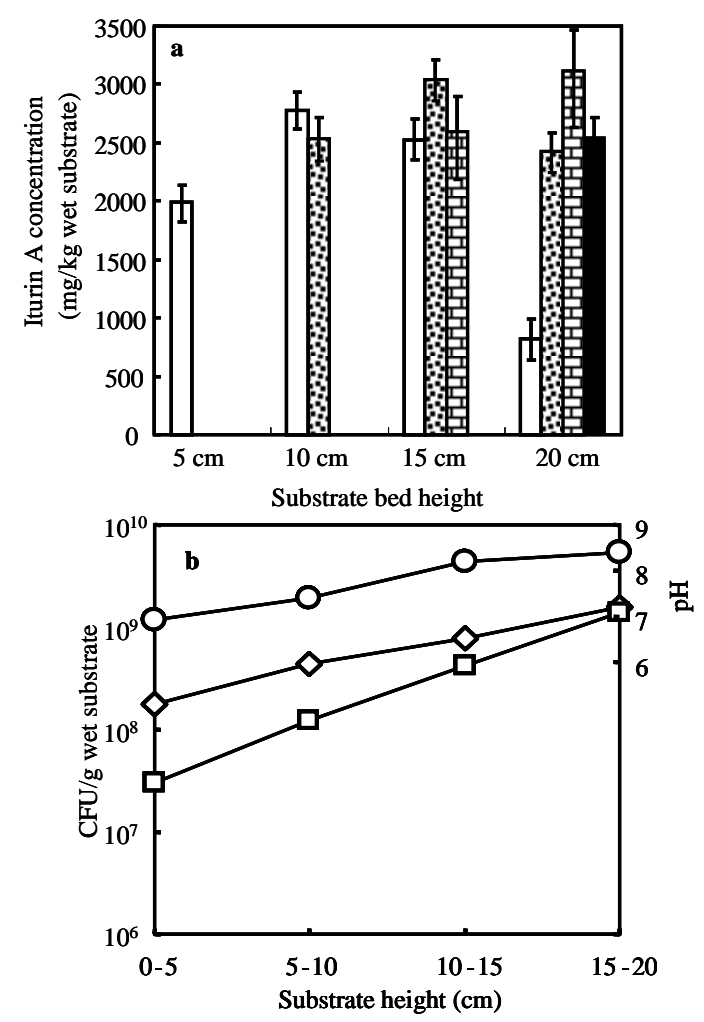

Figure 5. SSF in GCR system, figure (a) represents iturin A production when SSF was conducted at different substrate bed height. Open bar is for 0 - $5 \mathrm{~cm}$, part "D"; doted bar is for 5 $10 \mathrm{~cm}$, part "C"; brick bar is for $10-15 \mathrm{~cm}$, part "B" and solid bar is for 15 - $20 \mathrm{~cm}$, part “A”. (circle), (diamond) and (square) are shown $\mathrm{pH}$, total cell and spore respectively; (b) represents CFU and $\mathrm{pH}$ at different position of $20 \mathrm{~cm}$ high substrate bed.

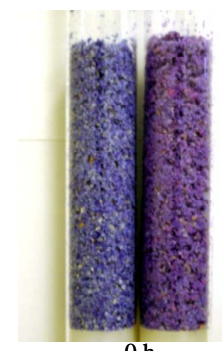

$0 \mathrm{~h}$

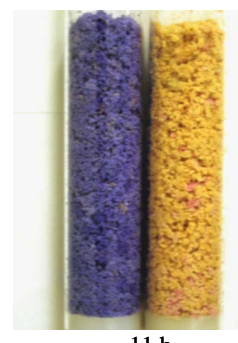

$11 \mathrm{~h}$
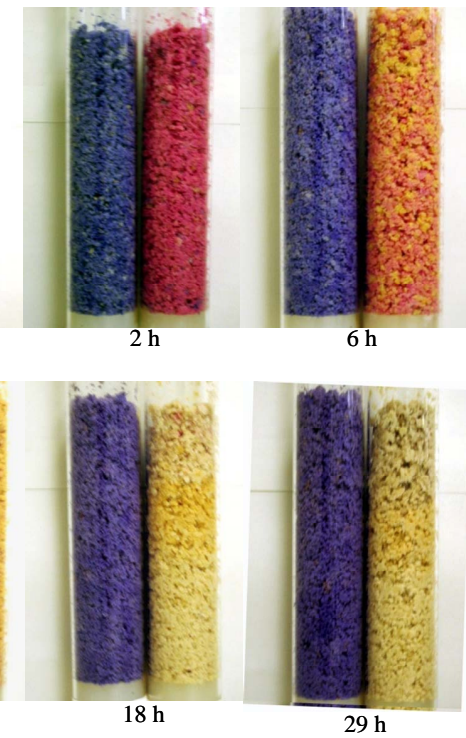

Figure 6. Oxygen depletion in GCR using Resazurin as an indicator. Images were taken at specific intervals $(0,2,6,11,18,29 \mathrm{~h})$ for control (without inoculation, left reactor) and experimental (with inoculation, right reactor) columns. clearly on 2nd h after incubation and the color was lost completely at 18th h (Figure 6).

Ohno et al. (1993) reported that first day aeration was critical for the production of iturin by Bacillus even though iturin was most rapidly produced during $48-72 \mathrm{~h}$ of the incubation in the stationary growth phase where the oxygen requirement is relatively lower [14]. From resazurin test result and the findings of Ohno et al. (1993) it can be said that Bacillus got its necessary oxygen during the first $18 \mathrm{~h}$ of incubation period for iturin A production and its growth. As the top of the GCR was covered by cotton plug (Figure 1), there was a possibility of small but continuous oxygen supply from environment into the GCR, thus a good amount of iturin A production in GCR up to $15 \mathrm{~cm}$ high substrate bed was observed. Recent studies show that $B$. subtilis can grow in anaerobic condition [15] however the production of lipopeptide like iturin A is really interesting.

\section{CONCLUSION}

Every year a huge amount of food industry organic wastes are being produced all over the world. SSF is a very well known technique to utilize these bulk amounts of solid wastes. Several techniques have been developed for efficient SSF to produce microbial metabolites. Substrate bed height is one of the major problems for efficient SSF. In this study, SSF was successfully conducted at a $15 \mathrm{~cm}$ high substrate bed where remarkable amount of lipopeptide antibiotics Iturin A was observed. To our knowledge it is the highest substrate bed height for SSF and for microbial secondary metabolites production. GCR is found to be an effective technique for SSF at a higher substrate bed height. Further investigations are essential for SSF of bacteria in GCR system to produce microbial metabolites as well as scale up of substrate use.

\section{REFERENCES}

[1] Robinson, T., Singh, D. and Nigam, P. (2001) Solid-state fermentation: A promising microbial technology for secondary metabolite production. Applied Microbiology and Biotechnology, 55, 284-289. doi:10.1007/s002530000565

[2] Mizumoto, S., Hirai, M. and Shoda, M. (2006) Production of lipopeptide antibiotic iturin A using soybean curd residue cultivated with Bacillus subtilis in solid-state fermentation. Applied Microbiology and Biotechnology, 72, 869-875. doi:10.1007/s00253-006-0389-3

[3] Yang, S.Q., Yan, Q.J., Jiang, Z.Q., Li, L.T., Tian, H.M. and Wang, Y.Z. (2006) High-level of xylanase production by the thermophilic Paecilomyces themophila J18 on wheat straw in solid-state fermentation. Bioresource Technology, 97, 1794-1800. doi:10.1016/j.biortech.2005.09.007

[4] Khare, S.K., Jha, K. and Gandhi A.P. (1995) Citric acid 
production from okara (soy-residue) by solid-state fermentation. Bioresource Technology, 54, 323-325. doi:10.1016/0960-8524(95)00155-7

[5] Ohno, A., Ano, T. and Shoda, M. (1996) Use of soybean curd residue, okara, for the solid state substrate in the production of a lipopeptide antibiotic, iturin A, by Bacillus subtilis NB22. Process Biochemistry, 31, 801-806. doi:10.1016/S0032-9592(96)00034-9

[6] Ohno, A., Ano, T. and Shoda, M. (1995) Effect of temperature on production of lipopeptide antibiotics, iturin A and surfactin by a dual producer, Bacillus subtilis RB14, in solid-state fermentation. Journal of Fermentation and Bioengineering, 80, 517-519. doi:10.1016/0922-338X(96)80930-5

[7] Hiraoka, H., Ano, T. and Shoda, M. (1992) Characteristics of Bacillus subtilis RB14, copoducer of peptide antibiotics iturin A and surfactin. The Journal of General and Applied Microbiology, 38, 635-640. doi:10.2323/jgam.38.635

[8] Phae, C.G., Shoda, M. and Kubota. H. (1990) Suppressive effect of Bacillus subtilis and its products on phytopathogenic microorganisms. Journal of Fermentation and Bioengineering, 69, 1-7. doi:10.1016/0922-338X(90)90155-P

[9] Asaka, O. and Shoda, M. (1996) Biocontrol of Rhizoctonia solani damping off of tomato with Bacillus subtilis RB14. Applied and Environmental Microbiology, 62, 4081-4085.

[10] Mizumoto, S., Hirai, M. and Shoda, M. (2007) Enhanced iturin A production by Bacillus subtilis and its effect on suppression of the plant pathogen Rhizoctonia solani. Applied Microbiology and Biotechnology, 75, 1267-1274. doi:10.1007/s00253-007-0973-1

[11] Ohno, A., Ano, T. and Shoda, M. (1995) Production of a lipopeptide antibiotic, surfactin, by recombinant Bacillus subtilis in solid-state fermentation. Biotechnology and Bioengineering, 47, 209-214. doi:10.1002/bit.260470212

[12] Phae, C.G. and Shoda, M. (1991) Investigation of optimal conditions for foam separation of iturin, an antifungal peptide produced by Bacillus subtilis. Journal of Fermentation and Bioengineering, 71, 118-121. doi:10.1016/0922-338X(91)90235-9

[13] O’brien, J., Wilson, I., Orton, T. and Pognan, F. (2000) Investigation of the alamar blue (resazurin) fluorescent dye for the assessment of mammalian cell cytotoxicity. European Journal of Biochemistry, 267, 5421-5426. doi:10.1046/j.1432-1327.2000.01606.x

[14] Ohno, A., Ano, T. and Shoda, M. (1993) Effect of temperature change and aeration on the production of the antifungal peptide antibiotic Iturin by Bacillus subtilis NB22 in liquid cultivation. Journal of Fermentation and Bioengineering, 75, 463-465. doi:10.1016/0922-338X(93)90098-S

[15] Nakano, M.M. and Zuber, P. (1998) Anaerobic growth of a "strict aerobe" (BACILLUS SUBTILIS). Annual Review of Microbiology, 52, 165-190. doi:10.1146/annurev.micro.52.1.165 